\title{
Results of five-year systematic screening for latent tuberculosis infection in healthcare workers in Portugal
}

\author{
José Torres Costa ${ }^{1,2,3^{*}}$, Rui Silva ${ }^{1,2,3}$, Raul Sá1, Maria João Cardoso ${ }^{4}$, Albert Nienhaus ${ }^{5}$
}

\begin{abstract}
Introduction: The risk of tuberculosis (TB) in healthcare workers (HCWs) is related to its incidence in the general population, and increased by the specific risk as a professional group. The prevalence of latent tuberculosis infection (LTBI) in HCWs in Portugal using the tuberculin skin test (TST) and the interferon-g release assays (IGRA) was analyzed over a five-year period.

Methods: A screening programme for LTBI in HCWs was conducted, with clinical evaluations, TST, IGRA, and chest radiography. Putative risk factors for LTBI were assessed by a standardised questionnaire.

Results: Between September 2005 and June 2009, 5,414 HCWs were screened. The prevalence of LTBI was 55.2\% and $25.9 \%$ using a TST $\geq 10 \mathrm{~mm}$ or an IGRA test result (QuantiFERON-TB Gold In-Tube) INF-g $\geq 0.35 \mathrm{IU} / \mathrm{mL}$ as a criterion for LTBI, respectively. In $53 \mathrm{HCWs}$ active TB was diagnosed. The number of HCWs with newly detected active TB decreased from 19 in the first year to 6 in 2008. Risk assessment was poorly related to TST diameter. However, physicians (1.7\%) and nurses (1.0\%) had the highest rates of active TB.

Conclusions: LTBI and TB burden among HCWs in Portugal is high. The screening of these professionals to identify HCWs with LTBI is essential in order to offer preventive chemotherapy to those with a high risk of future progression to disease. Systematic screening had a positive impact on the rate of active TB in HCWs either by early case detection or by increasing the awareness of HCWs and therefore the precautions taken by them.
\end{abstract}

\section{Introduction}

With the advent of antibiotics, many infectious diseases such as tuberculosis (TB) seemed well under control [1]. This feeling of security led to an absence of investment in implementing preventive measures and of training and education for healthcare workers (HCWs) on the risk of nosocomial infections and occupational diseases [2]. The emergence of groups with epidemic TB infection, i.e. HIV/AIDS-patients, further aggravated the situation [3].

In HCWs, the risk of TB infection is increased by exposure to patients with infectious disease, insufficient use of protective equipment such as respirators, and working conditions, particularly in inadequately ventilated areas and when conducting techniques which involve exposure to contaminated aerosols [3,4]. Given

\footnotetext{
* Correspondence: zecatoco@sapo.pt

${ }^{1}$ Occupational Health Division, Hospital S. João, EPE - Porto, Portugal
}

this higher risk of contracting the disease by exposure to M. tuberculosis in the workplace, in Portugal it is considered an occupational disease [5]. The incidence of TB in HCWs is related to the incidence in the general population in that geographical area. Added to this is the specific risk as a professional group, which depends on the type of health unit, workgroup, and efficiency in the implementation of infection control measures [6-9].

According to official records, the average rate of TB reported in the general population in Portugal is 29.4/ 100,000 , which means that, despite the reduction observed in recent years, it still has the highest incidence in the EU excluding the countries of the 2004 enlargement [10]. Despite the mandatory notification of active TB, there are no official records in Portugal of the number of affected HCWs [11].

Early diagnosis and effective treatment of patients, early recognition of possible contacts, the adoption of protective measures and the effective screening for cases 
of latent tuberculosis infection (LTBI) are all necessary for controlling the risk of TB in HCWs $[9,12,13]$. The diagnosis of recent cases of LTBI (conversion) is particularly important since the lifetime risk of progression to active disease ranges from 10 to $20 \%[12,14]$. According to several studies, the treatment of LTBI reduces the risk of developing active TB by more than 50\% [15-17], and is therefore one of the main objectives of a screening programme.

Until a few years ago, contacts were screened for conversions using the tuberculin skin test (TST) [18]. In recent years, advances in molecular biology have led to the development of new in-vitro tests that measure the levels of interferon-g released by sensitized $T$ lymphocytes after stimulation with antigens of $M$. tuberculosis. These interferon-g release assays (IGRA) do not present cross-reaction with Bacillus Calmet-Guérin (BCG), nor with the majority of nontuberculous mycobacteria [19]. Several HCW studies using IGRA have been performed so far comparing TST to IGRA [20-25]. While systematic screening of HCWs for TB started in 2005 at the S. João Hospital in Porto, Portugal, IGRA testing was introduced to the screening process in 2007. The subgroup in which TST and IGRA were performed simultaneously is described in previous papers [22,23]. In this paper we describe the results of the screening programme for the whole group that was screened between 2005 and 2009. Special emphasis is placed on workplace risk factors that might account for LTBI or active TB in HCWs.

\section{Methods}

The risk of $M$. tuberculosis infection was assessed in 5,524 HCWs working or training in our hospital between September 2005 and June 2009 (Figure 1). According to the latest CDC guidelines (2005) and based on the number of beds and patients diagnosed with TB each year (average of 258 patients, and 17.2 HCWs per TB patient ratio), the hospital is classified as a "medium risk" institution [9]. This screening was done on a regular annual basis, whenever new staff were employed, following occasional requests from symptomatic workers, or in cases of contact with infectious patients or materials. The risk of transmission of TB was classified as low, moderate and high, according to the CDC [9].

This screening programme consisted of: 1) a standardized interview covering gender, age, workplace, exposure situation, TB history and TB-related respiratory symptoms (cough, productive cough, haemoptysis, thoracalgia) as well as constitutional symptoms (fatigue, weight loss, fever and night sweat), 2) chest radiography (CXR) if TST or IGRA were positive or if symptomatic, 3) TST with $0.1 \mathrm{~mL}$ of 2 units of purified tuberculin
(PPD) RT 23 SSI, unless contraindication (previous tuberculin reaction $\geq 15 \mathrm{~mm}$, previous diagnosis of TB with appropriate treatment, severe viral infection or immunisation with vaccine with live virus less than 1 month ago, large extensive burns or eczema), and 4) since April 2007 in-vitro enzyme immunoassay (ELISA) test based on the quantification of interferon-g, QuantiFERON-TB Gold In-Tube (IGRA). This test was carried out simultaneously with the TST [26]. A TST $\geq 10 \mathrm{~mm}$ was considered as positive, in accordance with Portuguese guidelines [13]. IGRA tests were carried out on the basis of the manufacture's manual and considered positive when $\geq 0.35 \mathrm{IU} / \mathrm{mL}$. Undetermined IGRA results were repeated once. If screening was performed as a result of unprotected contact with infectious patients or materials, TST and IGRA were performed eight weeks after contact and CXR was performed 3 months and 12 months after contact.

Active TB was defined as infection with M. tuberculosis, with or without symptoms and/or clinical signs, typical CXR and confirmed microbiologically. LTBI was defined as infection with $M$. tuberculosis, without any clinical manifestation, and was diagnosed if TST $\geq 10 \mathrm{~mm}$ or IGRA $>0.35 \mathrm{IU} / \mathrm{mL}$ after exclusion of active TB regardless of CXR results due to the low sensitivity and specificity of CXR for the diagnosis of LTBI. The prevalence of LTBI when taking up employment (first week of employment) was compared with followup examinations.

Only in a subgroup were IGRA and TST performed simultaneously. This is because IGRA testing was introduced two years after the start of the systematic screening. The probability of a positive IGRA based on TST results was calculated for this subgroup. These probabilities were multiplied by the number of HCWs in the whole study group who had the same TST results. Adding up these products gave the number of HCWs that can reasonably be expected to be IGRA-positive in the whole group if they had all been tested with IGRA. This allowed the proportion of IGRA-positive HCWs in the whole study group to be estimated.

Statistical analysis was performed using a two-tailed chi-square test to compare proportions of positive tests (TST and IGRA) and Student $\hat{A}^{\prime}$ 's t-test, and a simple analysis of variance (one way ANOVA) to compare means and standard deviations between groups. A p-value $<0.05$ was considered statistically significant. Analysis was carried out with SPSS, Version 14.

The evaluation was carried out according to the objectives of the Commission for the Prevention and Control of Tuberculosis of Hospital S. João, no additional data was collected, and the analysis was carried out anonymously. For these reasons it was not necessary to request approval by the Ethics Committee. 


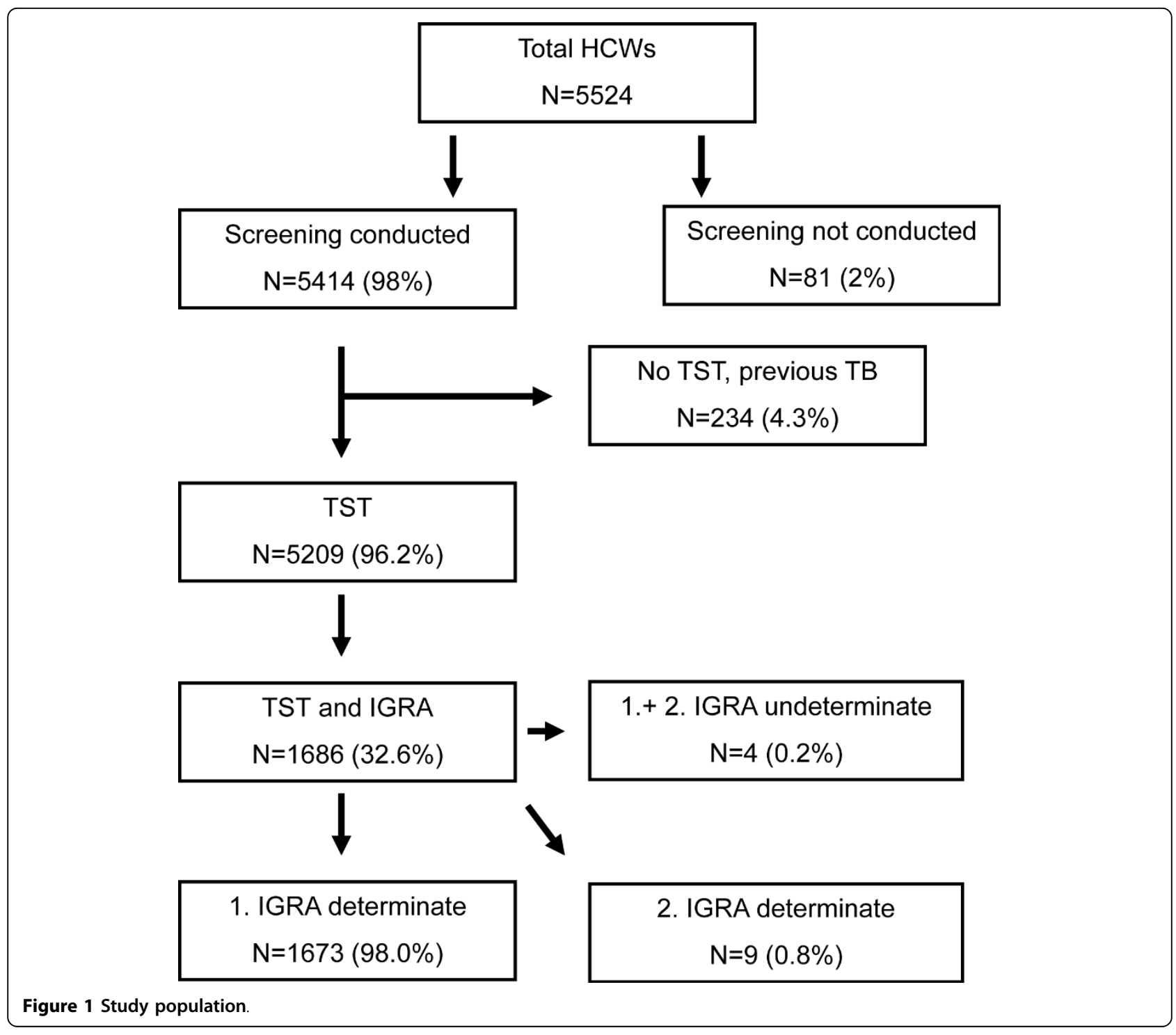

\section{Results}

The study comprises 5,524 HCWs working or training between September 2005 and June 2009 in our Hospital. TST results are available for 5,209 HCWs (Figure 1). Due to active TB in their medical history, TST was not performed in 234 (4.3\%) HCWs. Of these, 33 did not know the year of diagnosis, 88 reported that it had occurred before working as HCW and 113 afterwards. Based on clinical evaluation and CXR, none of these 234 HCWs had active TB at the time of screening.

$32.9 \%$ of the HCWs had a TST $\geq 15 \mathrm{~mm}$ and $55.2 \%$ $(32.9 \%+22.3 \%)$ had a TST $\geq 10 \mathrm{~mm}$ (Table 1$)$. BCG vaccination did not increase the probability of a large TST diameter, with $63.2 \%$ of those with a TST $<5 \mathrm{~mm}$ compared to $53.9 \%$ of those with a TST $\geq 15 \mathrm{~mm}$ having a record of BCG vaccination or a vaccination scar. Those with a TST $\geq 15 \mathrm{~mm}$ were older and employed for longer time as HCWs than those with a smaller TST diameter (p-value for both trends 0.001). Surprisingly, those with workplaces or tasks assumed to be of low risk most often showed a TST $\geq 15 \mathrm{~mm}$ (37\% versus $31 \%$ for moderate and $33.8 \%$ for high risk). On the other hand, they were less likely to have a TST $\leq 5 \mathrm{~mm}$ (25.7\% versus $34.7 \%$ for moderate and $31.7 \%$ for high risk) (p-value 0.001). Again surprisingly, physicians were less likely to have a TST $\geq 15(25.1 \%$ versus $38.4 \%$ among operational assistants) and more likely to have a TST $\leq 5 \mathrm{~mm}$ (41.4\% versus $22.6 \%$ among administrative assistants, Table 2) (p-value 0.013).

Since 2005, 53 cases of active TB have been diagnosed (Table 3), of which 19 occurred in 2005, the year the systematic screening started. This was also the year with the highest rate of active TB in the screening population. The number of HCWs with active TB in the 
Table 1 Risk factors for LTBI by TST

\begin{tabular}{|c|c|c|c|c|}
\hline & \multicolumn{4}{|c|}{ TST in $\mathrm{mm}$} \\
\hline & $<5$ & $\begin{array}{l}\geq 5- \\
<10\end{array}$ & $\begin{array}{l}\geq 10- \\
<15\end{array}$ & $\geq 15$ \\
\hline & $\mathrm{N}(\%)$ & N (\%) & N (\%) & N (\%) \\
\hline BCG scar or record (\%) & $\begin{array}{l}1061 \\
(63.2)\end{array}$ & $\begin{array}{c}446 \\
(68.3)\end{array}$ & $714(61.3)$ & $924(53.9)$ \\
\hline Age \pm SD (years) & $35 \pm 10.7$ & $\begin{array}{l}37 \pm \\
11.9\end{array}$ & $39 \pm 12$ & $41 \pm 10.7$ \\
\hline $\begin{array}{l}\text { Duration of exposure } \pm \\
\text { SD }\end{array}$ & $9 \pm 9.6$ & $\begin{array}{l}12 \pm \\
11.3 \\
\end{array}$ & $13 \pm 11.6$ & $16 \pm 10.8$ \\
\hline Low Risk (row\%) & $215(25.7)$ & $\begin{array}{c}100 \\
(12.0) \\
\end{array}$ & $212(25.4)$ & $309(37.0)$ \\
\hline Moderate risk & $897(34.7)$ & $\begin{array}{c}331 \\
(12.8)\end{array}$ & $558(21.6)$ & $802(31.0)$ \\
\hline High risk & $566(31.7)$ & $\begin{array}{c}222 \\
(12.4)\end{array}$ & $394(22.1)$ & 603 (33.8) \\
\hline All (\%) & $\begin{array}{l}1678 \\
(32.2)\end{array}$ & $\begin{array}{c}653 \\
(12.5)\end{array}$ & $\begin{array}{l}1164 \\
(22.3)\end{array}$ & $\begin{array}{l}1714 \\
(32.9)\end{array}$ \\
\hline
\end{tabular}

population declined in the following years: 13 in 2006, 14 in 2007, 6 in 2008 and $1 \mathrm{HCW}$ with active TB in the first six month of 2009. HCWs considered to be at low risk of $\mathrm{TB}$ exposure were less likely to have active $\mathrm{TB}$ $(0.5 \%)$ than those with moderate $(1.3 \%)$ or high risk of exposure $(0.9 \%)$ (p-value 0.023$)$. Contrary to the probability of a TST $\geq 10 \mathrm{~mm}$, which was second lowest for physicians among all of the HCWs screened, the probability of active TB was highest for physicians (1.7\%) followed by nurses (1.0\%) (p-value 0.034 ).

IGRA was performed in 1,686 HCWs (Table 4). For $13(<1 \%)$ HCWs IGRA was indeterminate. This remained the case for 4 of these after the second determination. The subgroup with determinate IGRAs $(\mathrm{n}=$ $1,682)$ was comparable to the whole group $(n=5209)$ in which TST was performed with respect to gender (female $72 \%$ versus $72 \%$ ), age (36 years Std 10.8 versus

Table 2 Profession by TST

\begin{tabular}{|c|c|c|c|c|}
\hline & \multicolumn{4}{|c|}{ TST in $\mathrm{mm}$} \\
\hline & $<5$ & $\geq 5-<10$ & $\geq 10-<15$ & $\geq 15$ \\
\hline & N (\%) & N (\%) & $\mathrm{N}(\%)$ & N (\%) \\
\hline Operational Assistent & $234(35.2)$ & $\begin{array}{c}108 \\
(16.3)\end{array}$ & $166(25.0)$ & $256(38.6)$ \\
\hline $\begin{array}{l}\text { Administrative } \\
\text { Assistent }\end{array}$ & $76(22.6)$ & $47(14.0)$ & $84(25.0)$ & $129(38.4)$ \\
\hline Nurse & $533(28.8)$ & $\begin{array}{c}202 \\
(10.9) \\
\end{array}$ & $419(22.7)$ & $695(37.6)$ \\
\hline Physician & $528(41.4)$ & $\begin{array}{c}162 \\
(12.7) \\
\end{array}$ & $264(20.7)$ & $320(25.1)$ \\
\hline Technician & $163(35.4)$ & $73(15.8)$ & $99(21.5)$ & $126(27.3)$ \\
\hline Others & $144(27.4)$ & $61(11.6)$ & $132(25.1)$ & $188(35.8)$ \\
\hline All (\%) & $\begin{array}{l}1678 \\
(32.2)\end{array}$ & $\begin{array}{c}653 \\
(12.5)\end{array}$ & $\begin{array}{l}1164 \\
(22.3)\end{array}$ & $\begin{array}{l}1714 \\
(32.9)\end{array}$ \\
\hline
\end{tabular}

Table 3 Distribution of active TB cases since 2005 ( $n=$ 53) according to risk and profession

\begin{tabular}{lccccc}
\hline & \multicolumn{2}{c}{ TST pos } & \multicolumn{2}{c}{ Active TB } & Total \\
\hline Risk & $\mathbf{N}$ & $\mathbf{\%}$ & $\mathbf{N}$ & $\mathbf{\%}$ & $\mathbf{N}$ \\
\hline Low & 521 & 62.3 & 4 & 0.5 & 836 \\
\hline Moderate & 1360 & 52.6 & 33 & 1.3 & 2588 \\
\hline High & 997 & 55.9 & 16 & 0.9 & 1785 \\
\hline Profession & & & & & \\
\hline Operational Assistent & 422 & 63.6 & 6 & 0.9 & 664 \\
\hline Administrative Assistent & 213 & 63.4 & 0 & - & 336 \\
\hline Nurse & 1114 & 60.3 & 18 & 1.0 & 1849 \\
\hline Physician & 584 & 45.8 & 21 & 1.7 & 1274 \\
\hline Technician & 225 & 40.1 & 4 & 0.7 & 561 \\
\hline Others & 320 & 61.0 & 3 & 0.6 & 525 \\
\hline All & 2878 & 55.3 & 53 & 1.0 & 5209 \\
\hline
\end{tabular}

38 years Std 11); and duration of employment in healthcare (11 years Std 10.5 years versus 12 years Std 11, no table).

Out of 1,682 HCWs with a determined IGRA, 558 (33.2\%) were positive. Probability of a positive IGRA increased with the diameter of the TST. However, even with a diameter of $\geq 15 \mathrm{~mm}$ only $49.2 \%$ of these HCWs had positive IGRA results (Table 4). Applying the probabilities of a positive IGRA for the different diameter category of the TST to all HCWs tested with TST produces a positive IGRA rate of $25.9 \%$ (calculated from Table 1 and Table 3).

Comparing the prevalence of LTBI found during the first week of employment $(n=1144)$ and follow-up examinations $(n=4062)$, a significantly higher prevalence was found in the latter, with $17.7 \%$ versus $29.0 \%$ using IGRA and $38.0 \%$ versus $60.1 \%$ using TST as a criterion for determining LTBI (no table, p-values for both IGRA and TST $<0.001)$.

\section{Discussion}

Our descriptive data show that the TB burden among Portuguese HCWs is high with 53 out of 5,209 (1\%) being diagnosed with active TB in the five-year period from 2005 to 2009. Accordingly, the prevalence of LTBI

Table 4 IGRA and TST in subgroup simultaneously tested [23]

\begin{tabular}{lcccccc}
\hline & \multicolumn{3}{c}{ IGRA } & \multicolumn{3}{c}{ All } \\
\hline TST in $\mathbf{~ m m}$ & pos & $\%$ & neg & $\%$ & N & Col\% \\
\hline$<5$ & 10 & 5.3 & 177 & 94.7 & 187 & 11.1 \\
\hline$\geq 5-<10$ & 23 & 12.9 & 155 & 87.1 & 178 & 10.6 \\
\hline$\geq 10-<15$ & 168 & 28.4 & 423 & 71.6 & 591 & 35.1 \\
\hline$\geq 15$ & 357 & 49.2 & 369 & 50.8 & 726 & 43.2 \\
\hline All & 558 & 33.2 & 1124 & 66.8 & 1682 & 100.0 \\
\hline
\end{tabular}


is high. However, estimates of LTBI prevalence vary to a great extent depending on whether prevalence is assessed with TST or IGRA (55\% versus $26 \%$ ).

Similar variations are found for HCWs in other countries, too. For instance, in a study involving 171 nurses from London the prevalence of LTBI was $16.2 \%$ by TST and $7.6 \%$ with the IGRA [27]. The relationship between TST and IGRA in this study is similar to the one we report, despite the much higher prevalence of LTBI in our hospital, which probably reflects differences between the two countries regarding the prevalence of LTBI in the general population $[7,10,28]$. In other studies, the prevalence of LTBI in HCWs has ranged from 22 to $41 \%$ with TST $(\geq 10 \mathrm{~mm})$ and of 10 to $40 \%$ with IGRA tests $[20,27,29,30]$. In a review conducted by Menzies et al in 2007 [7], the prevalence of LTBI in higher-income countries ranges from $11 \%$ to $30 \%$ (with TST), while in low-income countries it is estimated between $60 \%$ and $80 \%$ [21]. In Portugal there are no similar studies for comparison. If we accept the prevalence found in our hospital as representative of the country, Portugal would have a prevalence of LTBI in HCWs that is higher than in countries with high incomes but lower than in lowincome countries. In our previous publication, prevalence of LTBI was $33.2 \%$ when assessed by IGRA [23]. However, this figure seems to overestimate LTBI prevalence in the total screening population because IGRA was more often performed in HCWs with a higher TST. Prevalence of LTBI is more likely to be in the range of $25 \%$ for the whole screening population.

The incidence of $M$. tuberculosis infection in HCWs is related to the incidence in the general population in that geographical area. Added to this is the increased risk as a professional group and work conditions [6-9,31]. In a study by de Vries G et al [32], $67 \mathrm{HCWs}$ with TB were evaluated and it was determined that in $42 \%$ of these cases the infection had been acquired in the hospital, $28 \%$ in the community and $30 \%$ abroad.

Another concept for risk assessment examines the relationship between the number of admissions for TB with the number of HCWs. In hospitals with over 200 admissions per year, or a ratio between the number of HCWs and admissions for TB of less than $1 / 10$, the annual risk of infection (ARTI) in HCWs seems to be between 1 and $10 \%$ [2]. In the hospital where this study took place, the average number of admissions for TB as the primary diagnosis was 258 per year, giving a ratio of 17.2 HCWs (physicians and nurses) per TB admission and thus ranking it as a moderate-risk hospital [9].

The control of TB as a nosocomial infection requires, above all, the adoption of a "non-reactive" attitude, as it is known that most cases of TB transmission in hospitals occur in places where collective and individual measures of protection were not properly implemented (due to low probability of occurrence) [32]. Therefore, the rapid identification of patients with known or suspected active TB, the rapid implementation of airborne precautions and the use of a surgical mask or N95 respirator by the HCW are necessary measures for active protection. If $\mathrm{TB}$ patients are suspected of having MDR/XDR-TB, this might even warrant the use of more effective respirators for the HCWs. Given the low effectiveness of the BCG vaccination $[33,34]$, the strategy for preventing $\mathrm{TB}$ should be based on the identification and treatment of LTBI as a way of reducing the number of infected individuals, and the risk of progression to active TB [18].

In our study, the distribution of TB cases was not uniform over the years in question, with a maximum of 19 in 2005 (equivalent to 351/100.000), which is almost eight times higher than the incidence among the general population in the same geographical area (10). Since the implementation of this screening programme, there has been a significant reduction in TB cases. In 2008 only 6 cases of TB were diagnosed and in the first half of 2009 only 1 case. No new measures of infection control were implemented that might explain this effect. We believe that HCWsÂ' awareness of protective measures increased. They were therefore adhering to the rules more closely. Detection bias might also have a certain influence. At the start of the systematic screening there may have been some cases detected early or cases that would shortly have been detected anyway. In later years this leveled off towards early case detection.

Both TST and IGRA tests have limitations in the diagnosis of LTBI. The main problems with TST depend on technical limitations, difficulty in interpreting the results and the existence of a significant number of false positives $[13,35,36]$. On the other hand, IGRA tests, despite being more specific and having at least identical sensitivity to TST [20,37-39], present difficulties in interpreting results near the cut-off between positive/negative and also have higher unit costs $[24,40]$. The absence of a gold standard to correctly identify the sensitivity and specificity of each test poses a challenge [41]. The inability of both tests to distinguish between infection and immunological memory is a further shortcoming. A positive test indicates an immune response to stimulation by mycobacterial antigens, and not necessarily the existence of live $M$. tuberculosis in the human host. The percentage of individuals who are truly infected with $M$. tuberculosis after a TST or IGRA conversion is actually unknown. Therefore the term "latent infection" should be understood as the persistence of immune response and not necessarily as a potential risk for progression to disease [42].

To circumvent the booster effect problem, it is suggested to repeat the TST with a one-week interval (two steps), particularly in populations with high rates of BCG vaccination [13,43-45]. In this study, the difficult 
interpretation of this effect, the decrease in compliance by repetition of TST and the simultaneous use of IGRA tests were reasons for not performing the two-step TST systematically.

Risk assessment was not confirmed by distribution of TST diameter in our study, e.g. the highest proportion of TST $\geq 15 \mathrm{~mm}$ was observed in HCWs assumed to be at low risk of TB exposure. Two effects might explain this seemingly contradictory observation. First, risk classifications are based on a certain stability of professionals in the workplace [9], which generally is not observed. Second the habits, training and awareness necessary for taking personal protection measures, and socioeconomic characteristics of each group can confound the association between positive TST and risk assessment. Analysing the rate of active TB rather than positive TST gave a better association between perceived risk and actual TB burden, e.g. physician and nurses had the highest rates of active $\mathrm{TB}$ and those with low risk had the lowest rate of active TB.

Concerning limitations of the study, selection bias is of major concern. There is a certain selection bias because HCWs with recent contact with TB patients and HCWs with high TST diameters in their medical history are more likely to have screening performed. This explains why IGRA positivity is higher in the subgroup with simultaneous TST and IGRA testing than in the whole group. Therefore the rate of positive IGRAs estimated for the whole group is more likely to be the proportion of positive IGRA results $(25.9 \%)$ to be expected for HCWs in comparable hospitals in Portugal.

\section{Conclusions}

The TB burden in Portuguese HCWs working in comparable hospitals is high. The screening of these professionals is essential for an early diagnosis of active disease. It is also essential to identify cases with higher risk of future progression to disease as these professionals are most likely to benefit from preventive chemotherapy.

Since the implementation of this screening programme, the incidence of TB has decreased, which supports the importance of $\mathrm{TB}$ screening as a disease control measure, both by identifying high-risk cases and by alerting HCWs to this problem.

The authors declare that they do not have any direct or indirect personal relationship, affiliation or association with any party with whom they deal in their day to day work that would give rise to any actual or perceived conflict of interest.

\section{Acknowledgements}

We wish to thank all HCWs who participated in the screening for their cooperation

\section{Author details}

'Occupational Health Division, Hospital S. João, EPE - Porto, Portugal.

${ }^{2}$ Allergy Division, Hospital S. João, EPE - Porto, Portugal. ${ }^{3}$ Medical School, Oporto University, Porto, Portugal. ${ }^{4}$ Clinical Pathology Division, Hospital S. João, EPE - Porto, Portugal. ${ }^{5}$ Institute for Health Service Research in

Dermatology and Nursing, University Clinics Hamburg-Eppendorf, Germany.

\section{Authors' contributions}

JTC designed the study, performed the physical examinations, took part in data analyse and wrote the manuscript. RS was involved in data collection and analysis, and drafting of the paper. MJC was involved in designing the study and data collection, and gave substantial critical comments for manuscript writing. AN was involved in data analysis and gave substantial critical comments for manuscript writing. All authors have read and approved the final manuscript.

Received: 27 April 2010 Accepted: 26 July 2010 Published: 26 July 2010

\section{References}

1. Sepkowitz KA: Tuberculosis and the health care worker: a historical perspective. Ann Intern Med 1994, 120:71-9.

2. Menzies D, Fanning A, Yuan L, Fitzgerald M: Tuberculosis among Health Care Workers. N Engl J Med 1995, 332:92-8.

3. Baussano I, Bugiani M, Carosso A, Mairano D, Barocelli AP, Tagna M, Cascio V, Piccioni P, Arossa W: Risk of tuberculin conversion among healthcare workers and the adoption of preventive measures. Occup Environ Med 2007, 64:161-6.

4. Saleiro S, Santos A, Vidal O, Carvalho T, Torres Costa J, Marques JA: Tuberculosis in hospital department health care workers. Rev Port Pneumol 2007, 13(6):789-99.

5. Decreto Regulamentar n. $76 / 2007$, de 17 de Julho de 2007. Diário da República, 17 Julho 2007 (n. 136), Série I - Ministério do Trabalho e da Solidariedade Social.

6. Institute of Medicine: Tuberculosis in the workplace Washington, DC: National Academy Press 2001

7. Menzies D, Joshi R, Pai M: Risk of tuberculosis infection and disease associated with work in health care settings. Int I Tuberc Lung Dis 2007, 11(6):593-605.

8. Ratio $\mathrm{M}$, Tala E: Tuberculosis among health care workers during three recent decades. Eur Resp J 2000, 15:304-7.

9. Guidelines for Preventing the Transmission of Mycobacterium tuberculosis in Health-Care Settings. Department of health and human services. Centers for Disease Control and Prevention 2005.

10. DGS, SVIG-TB. 2006 [http://www.dgs.pt/upload/membro.id/ficheiros/ i009162.pdf], (accessed 16 July 2009).

11. Ministério do Trabalho e da Segurança Social - Estatísticas Disponíveis Doenças Profissionais. [http://195.245.197.202/left.asp?02.21.03.07], (accessed 16 July 2009).

12. Horsburgh CR: Priorities for the Treatment of Latent Tuberculosis Infection in the United States. N Engl J Med 2004, 350:2060-7.

13. Duarte R, Amado J, Lucas H, Sapage JM: Treatment of latent tuberculosis infection: update of guidelines, 2006 Portuguese Society of Pulmonology. Rev Port Pneumol 2007, 13(3):397-406.

14. Vynnycky E, Fine PE: Lifetime risks, incubation period, and serial interval of tuberculosis. Am J Epidemiol 2000, 152(3):247-63.

15. Centers for Disease Control and Prevention: Targeted tuberculin testing and treatment of latent tuberculosis infection. MMWR Morbidity Mortality Weekly Report 2000, 49(RR-6):1-5[http://www.cdc.gov/mmwr], (accessed 16 July 2009).

16. Reichler MR, Reves R, Bur S, Thompson V, Mangura BT, Ford J, Valway SE, Onorato IM: Evaluation of investigations conducted to detect and prevent transmission of tuberculosis. JAMA 2002, 287(8):991-5

17. Control and prevention of tuberculosis in the United Kingdom: code of practice 2000. Joint Tuberculosis Committee of the British Thoracic Society. Thorax 2000, 55(11):887-901.

18. Menzies D: What does tuberculin reactivity after Bacille Calmette-Guerin vaccination tell us? Clin Infect Dis 2000, 31(Suppl 3):S71-S74.

19. Andersen P, Munk ME, Pollock JM, Doherty TM: Specific immune-based diagnosis of tuberculosis. Lancet 2000, 356(9235):1099-1104.

20. Pai M, Gokhale K, Joshi R, Dogra S, Kalantri S, Mendiratta DK, Narang P, Daley CL, Granich RM, Mazurek GH, Reingold AL, Riley LW, Colford JM Jr: 
Mycobacterium tuberculosis infection in health care workers in rural India. Comparison of a whole blood interferon gamma assay with tuberculin skin testing. JAMA 2005, 293(22):2746-55.

21. Joshi R, Reingold AL, Menzies D, Pai M: Tuberculosis among health-care workers in low and middle-income countries: A systematic review. PLoS Med 2006, 3(12):e494.

22. Torres Costa J, Sá R, Cardoso MJ, Silva R, Ferreira J, Ribeiro C, Miranda M Plácido JL, Nienhaus A: Tuberculosis screening in Portuguese healthcare workers using the Tuberculin Skin Test and the Interferon-g release assay. Eur Resp J 2009, 34(6):1423-8.

23. Torres Costa J, Silva R, Sá R, Cardoso MJ, Silva R, Ribeiro C, Nienhaus A: Comparison of interferon-g release assay and tuberculin test for screening in healthcare workers. Rev Port Pneumol 2010, 16(2):211-21.

24. Tripoldi D, Brunet-Courtois B, Nael V, Audrain M, Chailleux E, Germaud P, et al: Evaluation of the tuberculin skin test and the interferon-g release assay for TB screening in French healthcare workers. J Occup Med Toxicol 2009, 4:30

25. Schablon A, Beckmann G, Harling M, Diel R Nienhaus A: Prevalence of latent tuberculosis among health care workers in a hospital for pulmonary diseases. J Occup Med Toxicol 2009, 4:1.

26. Rastreio e Tratamento de Tuberculose em Profissionais de Saúde. Comissão para a Prevenção e Controlo da Tuberculose (CPCT) do Hospital de São João 2008, (intranet/HSJ).

27. Khanna P, Nikolayevskyy V, Warburton F, Dobson E, Drobniewski F: Rate of latent tuberculosis infection detected by occupational health screening of nurses new to a London teaching hospital. Infect Control Hosp Epidemiol 2009, 30(6):581-4.

28. Ministério da Saúde e Direcção-Geral da Saúde: Plano Nacional de Saúde 2004-2010: Mais saúde para todos. Direcção-Geral da Saúde, Lisboa 2004

29. Pai M, Joshi R, Dogra S, Mendiratta D, Narang P, Kalantri S, Reingold A, Colford J, Riley L, Menzies D: Serial Testing of Health Care Workers for Tuberculosis Using Interferon-Assay. Am J Respir Crit Care Med 2006, 174:349-55.

30. LoBue PA, Catanzaro A: Control program at an urban teaching hospital. Effectiveness of a nosocomial tuberculosis. Chest 1998, 113:1184-9.

31. Nicas M: Regulating the risk of tuberculosis transmission among health care workers. AlHAJ 2000, 61:334-9.

32. Vries G, Ebek MM, Lambregts-van Weezen C: Healthcare workers with tuberculosis infected during work. Eur Resp J 2006, 28:1216-21.

33. Colditz GA, Brewer TF, Berkey CS: Efficacy of BCG vaccine in the prevention of tuberculosis. JAMA 1994, 271:698-702.

34. Rodrigues LC, Diwan VK, Wheeler JG: Protective effect of BCG against tuberculous meningitis and miliary tuberculosis: a meta-analysis. Int $J$ Epidemiol 1993, 22:1154-8.

35. Menzies D, Pai M, Comstock G: Meta-analysis: Tests for the diagnosis of latent tuberculosis infection: Areas of uncertainty and recommmendations for research. Ann Intern Med 2007, 146:340-54

36. Menzies D: Interpretation of repeated tuberculin tests. Boosting, conversion, and reversion. Am J Respir Crit Care Med 1999, 159:15-21.

37. Ewer K, Deeks J, Alvarez L, Bryant G, Waller S, Andersen P, Monk P, Lalvani A: Comparison of T-cell-based assay with tuberculin skin test for diagnosis of Mycobacterium infection in a school tuberculosis outbreak. Lancet 2003, 361:1168-73.

38. Gokhale P, Dogra J: Mycobacterium tuberculosis infection in health care workers in rural India: comparison of a whole-blood interferon gamma assay with tuberculin skin testing. JAMA 2005, 293(22):2746-7.

39. Kang YA, Lee H, Yoon H, Cho BL, Han SK, Shim YS, Yim JJ: Discrepancy between the tuberculin skin test and the whole-blood interferon gamma assay for the diagnosis of latent tuberculosis infection in an intermediate tuberculosis-burden country. JAMA 2005, 293(22):2785-7.

40. Álvarez-León E, Espinosa-Vega E, Santana-Rodríguez E, Molina-Cabrillana J, Pérez-Arellano J, Caminero J, Serrano-Aguilar P: Screening for Tuberculosis Infection in Spanish Healthcare Workers: Comparison of the QuantiFERON-TB Gold In-Tube Test with the Tuberculin Skin Test. Infect Control Hosp Epidemiol 2009, 30:876-83.

41. Kunst H, Khan K: New Tests for the Diagnosis of Latent Tuberculosis Infection. Ann Intern Med 2007, 147:673.

42. Mack U, Migliori G, Sester M, Rieder H, Lange C, et al: LTBI: latent tuberculosis infection or lasting immune responses to M. tuberculosis? A TBNET consensus statement. Eur Resp J 2009, 33:956-73.
43. Moreno S, Blázquez R, Novoa A, Carpena I, Menasalvas A, Ramírez C, Guerrero C: The Effect of BCG Vaccination on Tuberculin Reactivity and the Booster Effect Among Hospital Employees. Arch Intern Med 2001, 161:1760-5.

44. Menzies D, Fanning A, Yuan L, FitzGerald JM, the Canadian Collaborative Group in Nosocomial Transmission of TB: Hospital Ventilation and Risk for Tuberculosis Infection in Canadian Health Care Workers. Ann Intern Med 2000, 133:779-89.

45. Manangan L, Bennett C, Tablan N, Simonds D, Collazo G, Jarvis W: Nosocomial Tuberculosis Prevention Measures Among Two Groups of US Hospitals, 1992 to 1996. Chest 2000, 117:380-4.

doi:10.1186/1745-6673-5-22

Cite this article as: Torres Costa et al:: Results of five-year systematic screening for latent tuberculosis infection in healthcare workers in Portugal. Journal of Occupational Medicine and Toxicology 2010 5:22.

\section{Submit your next manuscript to BioMed Central and take full advantage of:}

- Convenient online submission

- Thorough peer review

- No space constraints or color figure charges

- Immediate publication on acceptance

- Inclusion in PubMed, CAS, Scopus and Google Scholar

- Research which is freely available for redistribution

Submit your manuscript at www.biomedcentral com/submit
Ciomed Central 